\title{
Process and Models of Decalcification of Bighead Carp Scale by Hydrochloric Acid
}

\author{
Yu-Mei HUANG ${ }^{1, a}$, You-Qin ZOU ${ }^{2, b}$, Bo-Quan JIANG ${ }^{1,2, c^{*}}$ \\ ${ }^{1}$ Department of Biology and Chemistry, Institute of Science, Nanchang University College of \\ Science and Technology, Nanchang, Jiangxi, 330029, P.R.China \\ ${ }^{2}$ School of Resources, Environmental and Chemical Engineering Nanchang University, 999 \\ XuefuRoad, Honggu new district Nanchang, Jiangxi, 330031, P.R.China \\ ahymxyz@163.com, bzouyouqin@ncu.edu.cn, cjbq_win@163.com \\ ${ }^{*}$ Corresponding author
}

Keywords: Bighead Crap, Fish Scale, Decalcification, Hydrochloric Acid, Models.

\begin{abstract}
Collagen is one of the important biological materials. Fish scale contains rich collagen. Extracting collagen from fish scale not only reduces the biological pollution but also receives good economic benefit. In this paper, based on the experimental results of single factor test made in our previous research work, the response surface method was used to further optimize the technical parameters for the decalcification of bighead fish scale and establish the process model and kinetic model. The results showed that the maximum calcium removal rate reached $86.61 \%$ under the optimal conditions of hydrochloric acid concentration $5.0 \%$, decalcification time $45 \mathrm{~min}$ and liquid/solid ratio 21.65 and the maximum decalcification velocity reached $0.4932 \mathrm{~g} /(\mathrm{L} \cdot \mathrm{min})$ under the optimal conditions of hydrochloric acid concentration $6.4 \%$, decalcification time 10.16 min and liquid/solid ratio 10.23. The two models in the form of multiple regression were proved to be basically identical with the actual values and they can be used to predict the calcium removal rate and decalcification velocity under different operation conditions and the decalcification velocity corresponding to the calcium removal rate under same conditions, to adjust the operation parameters for gaining the expected calcium removal rate and decalcification velocity, and to control the production capacity of fish scale treatment and the quality and production output of collagen prepared by following collagen extraction from the decalcified fish scale.
\end{abstract}

\section{Introduction}

Bighead carp, also called Aristichthys nobilis, is one of the "four famous fishes" (black carp, grass carp, silver carp and bighead carp) in our country and one of the China's major freshwater aquaculture species. With the development of China's aquaculture, the fish products processing has gotten a rapid development. In the fish products processing, a large number of scraps, including fish scales, fish skin, fish innards and fishbone, etc., are produced. At present, this kind of resource has not effectively utilized and only a small part of it is used as raw material to prepare feed in our country. Most of the fish scraps are abandoned, which not only pollutes the environment, but also causes the waste of resources. Therefore, comprehensively utilizing the fish scales is very significant to protect environment and develop the domestic economy[1-4]. Fish scales contain plenty of protein, mainly collagen, which accounts for about 50\% 60\% of total weight scales. Collagen is a kind of biological macromolecule material. It can supplement the nutrition for the skin layers, enhance the collagen activity of skin, have the functions of moisting skin, anti-aging, improving one's looks, eliminating wrinkle and raising hair etc. The fish scale contains a certain amount of hydroxyapatite. The collagen fibers are sticked with hydroxyapatite together, which will influence the process and quality of the collagen extraction of fish scale if hydroxyapatite or calcium is not removed as completely as possible before collagen extraction. The removal of hydroxyapatite is called decalcification process in which the calcium is dissolved from the apatite 
lattice of hydroxyapatite. In recent years, some researchers have done the studies on fish scale decalcification with EDTA, hydrochloric acid and citric acid as extracting agents. Most of them focused on the optimization of the operation conditions. Decalcification of fish scale is a process with reaction between acid and salt. The process model reflects the relations between calcium removal rate (as target) and main operation parameters(as influence factors). The kinetic model reflects the relations between decalcification velocity (as target) and main operation parameters(as influence factors). These two models can predict and adjust the technical parameters to achieve the expected alcium removal rate and decalcification velocity under different operation conditions, which is conductive to controlling the production capacity of fish scale treatment and collagen quality. In this paper, response surface method was used to further optimize the operation parameters and establish the process and kinetic models of decalcification from bighead fish scale and validate the models with the actual values, based on the results of single factor test method in our previous research work[5].

\section{Experimental}

\section{Raw materials}

Bighead carp scales: collected from local market. The scales were cleaned with distilled water and dried for use .

Chemicals: calcium carbonate,complexoneII(EDTA), hydrochloric acid, chrome black T, hydroxylamine hydrochloride, ethanol, ammonium chloride and ammonia. All the above are analytically pure.

\section{Standard Regression Equation of Calcium Concentration}

$5.00 \mathrm{~g}$ anhydrous calcium carbonate, dried to constant weight at $110{ }^{\circ} \mathrm{C}$, was accurately weighed and added into a breaker $(100 \mathrm{~mL})$. Then a small amount of distilled water and hydrochloric acid solution with concentration of $1 \mathrm{~mol} / \mathrm{L}$ were added into the breaker until the calcium carbonate was completely dissolved. After that, the solution was transferred to a $1000 \mathrm{ml}$ volumetric flask and diluted to scale. The concentration of calcium ion was $2 \mathrm{mg} / \mathrm{mL}$.

$$
y=0.02283 x-0.00439 \quad R=0.9996(p<0.0001)
$$

$0.00,1.00,2.00,3.00,4.00$ and $6.00 \mathrm{~mL}$ of standard calcium solution above were respectively added in 6 conical flasks $(250 \mathrm{~mL})$ and diluted to $20 \mathrm{~mL}$ with distilled water.Then $15 \mathrm{~mL}$ of ammonia buffer $(\mathrm{pH}=10)$ and 3 drops of chrome black $\mathrm{T}$ indicator were added into the flasks. The solution was measured by titration with $0.01 \mathrm{~mol} / \mathrm{L}$ EDTA standard solution until the color of the solution was changed from purple to blue. The consumed volume of EDTA was recorded. This measurement was conducted for two times in parallel. After that, the calcium standard curve was drawn with consumed volume of EDTA as the abscissa and calcium ion concentration as the ordinate[6]. The standard regression equation (liner equation) was obtained according to the standard curve.

\section{Measurement of Calcium Removal Rate}

$1 \mathrm{~g}$ bighead fish scales was accurately weighed and added in a $50 \mathrm{~mL}$ conical flask, then the hydrochloric acid solution with certain concentration and certain volume was added in flask. The flask was placed in a oscillator and the fish scales were decalcified under oscillation. After a certain time, the liquid-solid mixture was filtered and the filtrate was transferred to a $50 \mathrm{~mL}$ volumetric flask.The conical flask and filter paper were washed for three times with total $10 \mathrm{~mL}$ of distilled water.The washing water was merged into the filtrate and then diluted to scale.

$1.00 \mathrm{~mL}$ of the solution in the volumetric flask above was taken and transferred into a $250 \mathrm{~mL}$ conical flask and diluted with distilled water to $20 \mathrm{~mL}$. Then $15 \mathrm{~mL}$ ammonia buffer(pH=10) and 3 
drops of chrome black $\mathrm{T}$ indicator were added into the flask. The solution was measured by titration with $0.01 \mathrm{~mol} / \mathrm{L}$ EDTA standard solution until the color of it was changed from purple to blue and the consumed volume of EDTA was recorded. The calcium ion concentration in the decalcified solution was calculated by equation (1) and then the calcium removal rate (y) was calculated using following equation.

$$
y(\%)=\frac{c \times V_{1} \times V_{2}}{V_{3} \times m_{1} \times x \times 1000} \times 100
$$

Where $c$ is the calcium ion concentration calculated by equation $(1), \mathrm{mg} / \mathrm{mL} ; V_{1}$ is the diluted volume of the decalcified solution for titration, $\mathrm{mL} ; V_{2}$ : is the constant volume of the decalcified solution, $\mathrm{mL} ; V_{3}$ is the volume of decalcified solution from the $50 \mathrm{~mL}$ volumetric flask, $\mathrm{mL} ; m_{1}$ is the mass of bighead fish scale, $\mathrm{g} ; \mathrm{x}$ is the mass fraction of calcium in fish scale, 13.9\%[5].

\section{Measurement of Decalcification Velocity}

The decalcification velocity of fish scale is defined as mass of decalcified calcium per unit volume and per unit time, $\mathrm{g} /(\mathrm{L} \cdot \mathrm{min})$, which is calculated by following equation:

$$
v=\frac{y \times m_{1}}{V \times \tau} \quad(\mathrm{g} /(\mathrm{L} \cdot \min ))
$$

Where $\mathrm{V}$ is the volume of the hydrochloric acid solution, $\mathrm{mL}$; is the time of decalcification, min.

\section{Establishment of Models}

The suitable operation parameters for decalcification of bighead fish scale were determined by single factor test: mass fraction of hydrochloric acid 5\%, decalcification time $40 \mathrm{~min}$ and ratio of liquid/solid $20 \mathrm{~mL} / \mathrm{g}$, under which, the calcium removal rate reached $84.87 \%$ [5]. Based on the results of single factor test, the response surface test (Box-Behnken) was carried out in this experiment. Hydrochloric acid, decalcification time and ratio of liquid/solid were taken as investigation factors and calcium removal rate and decalcification velocity were taken as targets. The design of three factors with three levels was listed in Tab.1.

According to the design above, 17 sets of test (including 5 sets of central group tests) were separately conducted when the calcium removal rate and decalcification velocity were taken as targets and the results were listed in Tab.2.

The results of variance analysis of regression model with calcium removal rate and decalcification velocity as targets were exhibited in Table 3 and Table 4, respectively.

$$
\begin{aligned}
& \mathrm{Y}=-29.3288+88.3125 \mathrm{X}_{1}+2.0921 \mathrm{X}_{2}+3.6904 \mathrm{X}_{3}+0.0588 \mathrm{X}_{1} \mathrm{X}_{2}+0.1250 \mathrm{X}_{1} \mathrm{X}_{3}-0.0118 \mathrm{X}_{2} \mathrm{X}_{3}-74.50 \mathrm{X}_{1}^{2} \\
& -0.0203 \mathrm{X}_{2}^{2}-0.0731 \mathrm{X}_{3}^{2} \\
& \mathrm{Y}=0.6558+0,6450 \mathrm{X}_{1}-0.0124 \mathrm{X}_{2}+0.0265 \mathrm{X}_{3}-1.0000 \times 10^{-3} \mathrm{X}_{1} \mathrm{X}_{2}-2.0000 \times 10^{-3} \mathrm{X}_{1} \mathrm{X}_{3}+1.8250 \times 10^{-4} \mathrm{X}_{2} \mathrm{X}_{3} \\
& -0.5250 \mathrm{X}_{1}^{2}+6.4375 \times 10^{-5} \mathrm{X}_{2}^{2}+6.9250 \times 10^{-4} \mathrm{X}_{3}^{2}
\end{aligned}
$$

Tab.1 Test design of three factors/three levels for response surface method

\begin{tabular}{clccc}
\hline factor & \multicolumn{4}{c}{ levels } \\
& code & -1.00 & 0.00 & 1.00 \\
Hydrochloric acid concentration / (mass)\% & $\mathrm{X}_{1}$ & 4.00 & 5.00 & 6.00 \\
Decalcification time $/ \mathrm{min}$ & $\mathrm{X}_{2}$ & 20.00 & 40.00 & 60.00 \\
Ratio of liquid to solid/ $\mathrm{mL} / \mathrm{g}$ & $\mathrm{X}_{3}$ & 10.00 & 20.00 & 30.00 \\
\hline
\end{tabular}


Tab.2 Results of response surface method

\begin{tabular}{|c|c|c|c|c|c|c|c|c|c|}
\hline \multirow{4}{*}{$\begin{array}{c}\text { Ord } \\
\text { er } \\
\text { No. }\end{array}$} & \multirow{4}{*}{$\mathrm{X}_{1}$} & \multirow{4}{*}{$X_{2}$} & \multirow{4}{*}{$X_{3}$} & \multirow{4}{*}{$\begin{array}{r}\text { calcium } \\
\text { Test }\end{array}$} & \multirow{2}{*}{ removal } & \multirow{2}{*}{$\begin{array}{l}\text { rate } \\
\text { Model }\end{array}$} & \multicolumn{2}{|c|}{ decalcification } & \multirow{2}{*}{$\begin{array}{l}\text { velocity } \\
\text { relative }\end{array}$} \\
\hline & & & & & & & Test & Model & \\
\hline & & & & & relative es & & & error & \\
\hline & & & & & $\%$ & & $\mathrm{~g} /(\mathrm{L} \cdot \mathrm{min}$ & & $\%$ \\
\hline 1 & 4.00 & 20.00 & 20.00 & 67.57 & 69.10 & 2.26 & 0.235 & 0.240 & 2.13 \\
\hline 2 & 6.00 & 20.00 & 20.00 & 71.00 & 72.60 & 2.25 & 0.250 & 0.260 & 4.00 \\
\hline 3 & 4.00 & 60.00 & 20.00 & 80.80 & 79.20 & -1.98 & 0.094 & 0.085 & -9.57 \\
\hline 4 & 6.00 & 60.00 & 20.00 & 84.70 & 83.17 & -1.81 & 0.098 & 0.089 & -9.18 \\
\hline 5 & 4.00 & 40.00 & 10.00 & 69.95 & 71.53 & 2.26 & 0.243 & 0.250 & 2.88 \\
\hline 6 & 6.00 & 40.00 & 10.00 & 73.50 & 75.01 & 2.05 & 0.255 & 0.260 & 1.96 \\
\hline 7 & 4.00 & 40.00 & 30.00 & 79.94 & 78.43 & -1.89 & 0.093 & 0.085 & -8.60 \\
\hline 8 & 6,00 & 40.00 & 30.00 & 83.99 & 82.41 & -1.88 & 0.097 & 0.089 & -8.25 \\
\hline 9 & 5.00 & 20.00 & 10.00 & 61.47 & 58.36 & -5.06 & 0.42 & 0.41 & -2.38 \\
\hline 10 & 5.00 & 60.00 & 10.00 & 73.38 & 73.40 & 0.03 & 0.170 & 0.170 & 0.00 \\
\hline 11 & 5.00 & 20.00 & 30.00 & 70.24 & 70.22 & -0.03 & 0.163 & 0.160 & -1.84 \\
\hline 12 & 5.00 & 60.00 & 30.00 & 72.72 & 75.83 & 4.28 & 0.076 & 0.073 & -3.95 \\
\hline 13 & 5.00 & 40.00 & 20.00 & 84.90 & 84.90 & 0.00 & 0.150 & 0.150 & 0.00 \\
\hline 14 & 5.00 & 40.00 & 20.00 & 84.90 & 84.90 & 0.00 & 0.150 & 0.150 & 0.00 \\
\hline 15 & 5.00 & 40.00 & 20.00 & 84.90 & 84.90 & 0.00 & 0.150 & 0.150 & 0.00 \\
\hline 16 & 5.00 & 40.00 & 20.00 & 84.90 & 84.90 & 0.00 & 0.150 & 0.150 & 0.00 \\
\hline 17 & 5.00 & 40.00 & 20.00 & 84.90 & 84.90 & 0.00 & 0.150 & 0.150 & 0.00 \\
\hline
\end{tabular}

Tab.3 Results of variance analysis of regression model ( with calcium removal rate as target)

\begin{tabular}{ccccccc}
\hline Source & Sum of square & $\begin{array}{c}\text { Degree of freedom } \\
\text { DF }\end{array}$ & $\begin{array}{c}\text { Mean square } \\
\text { MS }\end{array}$ & F value & Prob $>F$ & $\begin{array}{c}\text { Significance } \\
\text { level } \\
\text { significant }\end{array}$ \\
model & 908.30 & 9 & 100.93 & 18.21 & 0.0005 & \\
$\mathrm{X}_{1}$ & 27.86 & 1 & 27.86 & 5.03 & 0.0599 & \\
$\mathrm{X}_{2}$ & 213.42 & 1 & 213.42 & 38.51 & 0.0004 & \\
$\mathrm{X}_{3}$ & 102.17 & 1 & 102.17 & 18.44 & 0.0036 & \\
$\mathrm{X}_{1} \mathrm{X}_{2}$ & 0.055 & 1 & 0.055 & $9.965 \times 10^{-3}$ & 0.9233 & \\
$\mathrm{X}_{1} \mathrm{X}_{3}$ & 0.063 & 1 & 0.063 & 0.011 & 0.9184 & \\
$\mathrm{X}_{2} \mathrm{X}_{3}$ & 22.23 & 1 & 22.23 & 4.01 & 0.0853 & \\
$\mathrm{X}_{1}{ }^{2}$ & 2.34 & 1 & 2.34 & 0.42 & 0.5368 & \\
$\mathrm{X}_{2}{ }^{2}$ & 278.82 & 1 & 278.82 & 50.31 & 0.0002 & \\
$\mathrm{X}_{3}{ }^{2}$ & 224.99 & 1 & 224.99 & 40.60 & 0.0004 & \\
Residual & 38.79 & 7 & 5.54 & & & Not significant \\
Lack of Fit & 38.79 & 3 & 12.93 & 4.69 & & \\
Pure error & 0.000 & 4 & 0.000 & & & \\
Total & 947.13 & 16 & & & & \\
variation & 0.9590 & & & & & \\
$\mathrm{R}^{2}$ & & & & & \\
\hline It can be seen from Table 3 that the model F-value of 18.21 implies the model is significant.
\end{tabular}

It can be seen from Table 3 that the model F-value of 18.21implies the model is significant. There is only a $0.05 \%$ chance that "a Model F-value"this large could occur due to noise. The values of " Prob $>F$ " less than 0.0500 indicate the model terms are significant, in this case, $\mathrm{X}_{2}, \mathrm{X}_{3}, \mathrm{X}_{2} \mathrm{X}_{3}$, $\mathrm{X}_{2}{ }^{2}$ and $\mathrm{X}_{3}{ }^{2}$ are significant model terms. The values of " Prob $>F$ " greater than 0.1000 indicate the model terms are not significant, in this case, $X_{1}, X_{1} X_{2}, X_{1} X_{3}$ and $X_{2} X_{3}$ are not significant model terms. The correlation coefficient of the model is $\mathrm{R}^{2}=0.9590$, which means that the model can well describe the test results and only $4.10 \%$ of total variation of response value can not be explained by the model. Furthermore, as shown in the $7^{\text {th }}$ column of "relative error" of Table 2 , the model values of calcium removal rate are basically close to the test values and their relative errors are ranged 
from $0.00 \%$ to $5.06 \%$ (absolute values), indicating that the model is basically accurate to predict and adjust the process parameters for gaining the expected calcium removal rate. According to the "Prob $>F$ " values of $\mathrm{X}_{1}, \mathrm{X}_{2}$, and $\mathrm{X}_{3}$ in Table 3, the significance of the effects of the three factors on the calcium removal rate can be determined to be $X_{2}>X_{3}>X_{1}$. The technical parameters were further optimized to be hydrochloric acid concentration 5\%, decalcification time $45 \mathrm{~min}$ and liquid/solid ratio 21.7 by the solution of the model (4) with the software. Under the optimal conditions, the maximum calcium removal rate was $86.61 \%$.

It can be seen from Table 4 that the model F-value of 82.83 implies the model is significant. There is only a $0.01 \%$ chance that "a Model F-value"this large could occur due to noise. The values of "Prob $>F$ " less than 0.0500 indicate the model terms are significant, in this case, $\mathrm{X}_{2}, \mathrm{X}_{3}, \mathrm{X}_{1}^{2}$, $\mathrm{X}_{2}{ }^{2}$ and $\mathrm{X}_{3}{ }^{2}$ are significant model terms. The values of " Prob $>\mathrm{F}$ " greater than 0.1000 indicate the model terms are not significant, in this case, $\mathrm{X}_{1}, \mathrm{X}_{1} \mathrm{X}_{2}, \mathrm{X}_{1} \mathrm{X}_{3}$ and $\mathrm{X}_{1}{ }^{2}$ are not significant model terms. The model "Prob $>F$ " value less than 0.0001 indicate that the relations between the response value (decalcification velocity) and the three factors are extremely significant and the test results are reliable. The correlation coefficient of the model is $\mathrm{R}^{2}=0.9907$, which means that the model can well describe the test results and only $0.93 \%$ of total variation of response value can not be explained by the model. Furthermore, as shown in the $10^{\text {th }}$ column of "relative error" of Table 2 , the model values of decalcification velocity are basically close to the test values and their relative errors are ranged from $0.00 \%$ to $9.57 \%$ (absolute values), indicating that the model is basically accurate to predict and adjust the process parameters for obtaining the expected decalcification velocity. According to the "Prob $>F$ " values of $\mathrm{X}_{1}, \mathrm{X}_{2}$ and $\mathrm{X}_{3}$ in Table 4, the significance of the effects of the three factors on the decalcification velocity can be determined to be $X_{2}>X_{3}>X_{1}$. The technical parameters were further optimized to be hydrochloric acid concentration $6.4 \%$, decalcification time $10.16 \mathrm{~min}$ and liquid/solid ratio 10.23 by the solution of the model (5) with the software. Under the optimal conditions, the maximum decalcification velocity was $0.4932 \mathrm{~g} /(\mathrm{L} \cdot \mathrm{min})$.

Tab. 4 Results of variance analysis of regression model (with decalcification velocity as target)

\begin{tabular}{ccccccc}
\hline Source & $\begin{array}{c}\text { Sum of } \\
\text { square }\end{array}$ & $\begin{array}{c}\text { Degree of freedom } \\
\text { DF }\end{array}$ & $\begin{array}{c}\text { Mean square } \\
\text { MS }\end{array}$ & F value & Prob $>F$ & $\begin{array}{c}\text { Significance } \\
\text { level }\end{array}$ \\
model & 0.12 & 9 & 0.014 & 82.83 & $<0.0001$ & significant \\
$\mathrm{X}_{1}$ & $1.280 \times 10^{-4}$ & 1 & $1.280 \times 10^{-4}$ & 0.77 & 0.4080 & \\
$\mathrm{X}_{2}$ & 0.053 & 1 & 0.053 & 319.52 & $<0.0001$ & \\
$\mathrm{X}_{3}$ & 0.058 & 1 & 0.058 & 351.76 & $<0.0001$ & \\
$\mathrm{X}_{1} \mathrm{X}_{2}$ & $1.600 \times 10^{-5}$ & 1 & $1.600 \times 10^{-5}$ & 0.097 & 0.7648 & \\
$\mathrm{X}_{1} \mathrm{X}_{3}$ & $1.600 \times 10^{-5}$ & 1 & $1.600 \times 10^{-5}$ & 0.097 & 0.7648 & \\
$\mathrm{X}_{2} \mathrm{X}_{3}$ & $5.329 \times 10^{-3}$ & 1 & $5.329 \times 10^{-3}$ & 32.24 & 0.008 & \\
$\mathrm{X}_{1}{ }^{2}$ & $1.161 \times 10^{-4}$ & 1 & $1.161 \times 10^{-4}$ & 0.70 & 0.4297 & \\
$\mathrm{X}_{2}{ }^{2}$ & $2.792 \times 10^{-3}$ & 1 & $2.792 \times 10^{-3}$ & 16.89 & 0.0045 & \\
$\mathrm{X}_{3}{ }^{2}$ & $3.602 \times 10^{-3}$ & 1 & $3.602 \times 10^{-3}$ & 21.79 & 0.0023 & \\
Residual & $1.157 \times 10^{-3}$ & 7 & $1.653 \times 10^{-4}$ & & & \\
Lack of Fit & $1.157 \times 10^{-3}$ & 3 & $3.857 \times 10^{-4}$ & & & Not significant \\
Pure error & 0.000 & 4 & 0.000 & & & \\
Total & 0.12 & 16 & & & & \\
variation & & & & & & \\
$\mathrm{R}^{2}$ & 0.9907 & & & & & \\
\hline
\end{tabular}

\section{Conclusions}

The technical parameters were further optimized by response surface method. The optimal parameters were determined to be hydrochloric acid concentration $5.0 \%$, decalcification time 45 min and liquid/solid ratio 21.65, under which the maximum calcium removal rate reached $86.61 \%$ and hydrochloric acid concentration $6.4 \%$, decalcification time $10.16 \mathrm{~min}$ and liquid/solid ratio 10.23 under which the maximum decalcification velocity reached $0.4932 \mathrm{~g} /(\mathrm{L} \cdot \mathrm{min})$. The models 
were basically in agreement with the test values. They can predict the calcium removal rate and decalcification velocity under different conditions and decalcification velocity corresponding to the calcium removal rate under same conditions which can adjust the parameters for gaining the expected calcium removal rate and decalcification velocity and control the production capacity of scale treatment and the collagen quality by following extraction from the decalcified fish scale.

\section{Acknowledgements}

This research was financially supported by Jiangxi province as a key project in achievements in science and technology(No. 20124ABE02104).

\section{References}

[1]Duan, R.,Zhang, J.J., Du, X.Q., Yao, X.C.,\& Konno Kunihiko: Food Chemistry 112(2009),p. 702.

[2]Kanokwan,Matmaaroh, Soottawat Benjakul, Thummanoon Prodpron, Angel B., Hideki Kishmura: Food Chemistry 129(2011), p.1179.

[3]Dasong Liu, Li Liang, Joe M., Regenstein, Pen:. Food Chemistry 133(2012),p. 1441.

[4]Jiangnan Zeng, Boquan Jiang, Linsheng Wei, Yafang Zhang:: Nanchang University (Engineering \& Technology) 33(2011),p.338.

[5] Ning Zhengxiang. Food composition analysis manual [M]. Beijing: China, Light Industry Press, 1998:579-583. 